\title{
Desarrollo urbanístico, control social e higiene en El Salvador (1859,1861-1863)
}

DOI: http://dx.doi.org/10.5377/koot.v0i9.5905

URI: http://hdl.handle.net/11298/435

\author{
Chester Urbina Gaitán \\ Catedrático e investigador \\ Universidad Nacional Heredia, Costa Rica \\ Contacto: chesterurbina@yahoo.com
}

\section{Resumen}

El desarrollo urbanístico de San Salvador durante los gobiernos del ex presidente Gerardo Barrios en 1859 y 1861 a 1863, señala que los principales locales profesionales y establecimientos comerciales que se abrieron fueron las oficinas de abogados. Esto se debe a la necesidad de contar con profesionales que legalizaran las transacciones de privatización de la tierra. La ebriedad y los juegos prohibidos fueron las principales entretenciones de los sectores populares que se trataron de controlar. Las principales enfermedades de los salvadoreños a mediados del siglo XIX eran las fiebres, la disentería, el catarro, los dolores agudos de estomago y las afecciones reumáticas. El poco apoyo a la morigeración de las costumbres de los sectores populares y al combate de las enfermedades antes mencionadas radica en que las finanzas públicas se dedicaron a la construcción de caminos, elementos necesarios para la economía agroexportadora añilera.

Palabras clave: Desarrollo urbano - El Salvador - 1859 - 1863, Urbanismo - El Salvador - 1859 - 1863, El Salvador - aspectos sociales -1859 - 1863, Desarrollo cultural, Higiene pública - El Salvador - 1859 - 1863.

\begin{abstract}
The urban development of San Salvador during the governments of former president Gerardo Barrios in 1859 and 1861 to 1863 , indicates that the main professional sites and commercial establishments that were opened were the firms of lawyers. This is due to the need to have professionals who legalize land privatization transactions. Drunkenness and forbidden games were the main types of entertainment of the popular sectors that were attempted to control. Moreover, the main diseases of Salvadorans in the mid-nineteenth century were fevers, dysentery, influenza, acute stomach pains, and rheumatic diseases. The
\end{abstract}


little support for the temperance of the habits of popular sectors and the battle against the aforementioned diseases lies in the fact that public finances were dedicated to the construction of roads, necessary elements for an agro-export indigo economy.

Keywords: Urban development - El Salvador - 1859 - 1863, Urbanism - El Salvador - 1859 - 1863, El Salvador - social features -1859 - 1863, Cultural development, Public hygiene - El Salvador - 1859 - 1863.

\section{Introducción}

El Salvador a mediados del siglo XIX se separa de la extinta República Federal de Centroamérica y se declara República independiente en 1859. La elite políticoeconómica salvadoreña comenzó a asumir la tarea de construcción de una base económica que sustentara al incipiente Estado y que le permitiera propagar un proyecto de nación. La economía agroexportadora gradualmente fue transitando del añil al café, el cual se asentara definitivamente en el último cuarto de siglo del siglo XIX. ${ }^{1}$ En 1859, San Salvador volvió a ser capital del país. Este traslado de la capital se debió a que cinco años atrás San Salvador había sido destruida por un terremoto quedando la capitalidad en la Nueva San Salvador, actual Santa Tecla. ${ }^{2}$ Este hecho se convirtió en un factor fundamental en la ausencia de locales idóneos para la presentación de nuevos productos y artefactos de entretenimiento. La crisis del añil y la quiebra del Estado salvadoreño por su protagonismo en las guerras federales no permitieron una vinculación fuerte a la economía mundial y a la cultura de masas y un despliegue amplio de nuevas formas de entretenimiento que trastocaran las practicas lúdicas de los habitantes capitalinos. ${ }^{3}$ Esto se confirma en un artículo titulado: "Entretenimiento y control social: San Salvador 1847-1875", donde se señala que antes de 1859 las principales festividades capitalinas eran las del Divino Salvador del Mundo.

También se celebraban corridas de toros, la presentación de una compañía de funámbulos en 1849 y las representaciones teatrales de la Sociedad Anónima del Teatro Nacional en 1852. Con respecto al control de los sectores considerados "peligrosos" para la sociedad san salvadoreña se tiene que a principios de 1854 se emiten disposiciones sobre la vagancia, la ebriedad, los juegos prohibidos, la fabricación y venta de aguardiente clandestino y chicha fuerte, los artesanos y jornaleros que faltaran al cumplimiento de sus contratos laborales y de los mendigos. Serian perseguidos y castigados como vagos los que no tuvieran oficio o modo de vivir conocidos y los que no lo ejercieran diariamente sin justa causa. Asimismo, los maestros y oficiales de cualquier

1 Para más información véase: Lindo-Fuentes, Héctor. (2002). La economía de El Salvador en el siglo XIX. San Salvador: CONCULTURA.

2 Gaceta del Salvador, Miércoles 2 de febrero de 1859, p.1.

3 López Bernal, Carlos Gregorio. (2007). Tradiciones inventadas y discursos nacionalistas: El imaginario nacional de la época liberal en El Salvador, 1876-1932. San Salvador: Editorial e Imprenta Universitaria, y Fernández, José Antonio. (2003). Pintando el mundo de azul. San Salvador: CONCULTURA. 


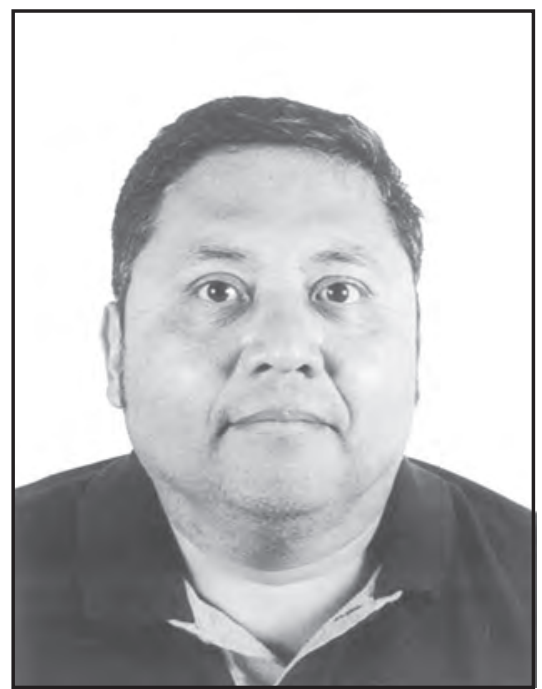

Máster e historiador Chester Urbina

arte y oficio, los jornaleros que en día de trabajo se encontraran en los billares, tabernas y casas de colmeria. Los aprendices que no llegaran diariamente a sus talleres y se encontraran vagando por las calles serian conducidos ante la autoridad y en presencia de ella sus maestros respectivos le aplicarían la pena de 6 a 12 azotes. Asimismo quedaban prohibidos los juegos de monte a los naipes, el de los dados, el de las tres cartas, el de la cinta, el de los dedales, el de la rueda de la fortuna, el de la roleta y todos los demás de envite, suerte y azar. Las mujeres consideradas como "vagamundas", ebrias de profesión, chicheras o contrabandistas de aguardiente serían recluidas en las poblaciones donde existieran hospitales, fábricas de salitre o pólvora por cuenta del Estado. Para 1859 se consigna que entre las costumbres de las personas que vivían en el Departamento de San Salvador estaban la de la ingesta de aguardiente, y la afición por la música, el baile y el matrimonio. Debido a la falta de policías y de una vigilancia constante estas disposiciones no fue acatada fielmente por los sectores considerados como "mal vivientes" de San Salvador, por lo que sus pautas de relacionamiento en el ámbito de lo lúdico no fueron transformadas radicalmente. ${ }^{4}$

Entre 1858 y 1863 se sucedieron varios gobiernos del Capitán General Gerardo Barrios, cuyo distanciamiento de los liberales y el poco tiempo que logró mantenerse en el poder, impidieron al caudillo, desarrollar un proyecto político consistente. Barrios gobernó mediante una red social de poder egocentrada, la mayoría de nodos de poder de este político estuvieron vinculados por lazos de parentesco, comercio y trayectoria militar. La tendencia a la subordinación 4 Urbina Gaitán, Chester. (2008). "Entretenimiento y Control Social: San Salvador 18471875". En http://www.efdeportes.com/ Revista Digital, 13, 120. Recuperado en http://www. efdeportes.com/efd120/entretenimiento-y-control-social-san-salvador-1847-1875.htm el 13 de julio de 2016. 
en estas vinculaciones, las convirtieron en lazos débiles. ${ }^{5}$ Una vez llegado a este punto es que el presente artículo tiene como objetivo estudiar el desarrollo urbanístico de San Salvador, el control social de los sectores populares y la política de higiene pública de los diferentes gobiernos del ex presidente Gerardo Barrios en 1859 y de 1861 a 1863. Para esto se emplearan los tomos disponibles de la Gaceta Oficial y Gaceta del Salvador de esos mismos años.

\section{Desarrollo urbanístico capitalino, sectores populares e higiene pública en El Salvador (1859, 1861-1863)}

Con respecto al desarrollo urbanístico de San Salvador en 1859, se sabe que el Lic. Juan Bosque vendía libros en su casa de habitación, ${ }^{6}$ los Licenciados Marcelino García ${ }^{7}$ y Manuel Cáceres ofrecían sus servicios como abogados, ${ }^{8}$ llegó la Compañía dramática-zarzuelista de doña Concepción Samaniego, ${ }^{9}$ funcionaba el molino de trigo de don José María Andrade de la calle de Marte ${ }^{10}$ y se abrió la cafetería de don Baudilio Alió. ${ }^{11}$ Además, funcionaba la botica de don Ambrosio Méndez ${ }^{12}$ y la imprenta de don Antonio Liévano. ${ }^{13}$ Asimismo don Juan Morel brindaba sus servicios como relojero y dorador, ${ }^{14}$ don Lisandro Melara abrió su hote ${ }^{15}$ y en la casa de la señora Medrano, ubicada en la calle del Comercio, el Dr. Juan W. Mc. Dowell brindaba sus servicios médicos. ${ }^{16}$

Para el año de 1861 don Manuel Argüello M. vendía harina de Chile en su casa de habitación cerca de la Merced, ${ }^{17}$ también funcionaba la sastrería de don Laureano Alemán ${ }^{18}$ y en el hotel de la esquina de la calle de Marte, de la plaza de Santo Domingo, residían los agentes de la Compañía General de Seguros Mutuos sobre la vida. ${ }^{19}$ Don Calixto Folly ofrecía sus servicios como profesor de música, ${ }^{20}$ el Dr. Gustavo Bernoulli se ponía a la orden del público en su casa

5 Alfaro Rivas, Edwin Alfredo. (2014). Las prácticas políticas en El Salvador a mediados del siglo XIX: Las redes sociales de Francisco Dueñas y Gerardo Barrios, 1854-1865. Informe final de investigación para optar al grado de Licenciado en Historia. Universidad de El Salvador. p.159. También véase: López Bernal, Carlos Gregorio. (2007). "Compadrazgos, negocios y política: las redes sociales de Gerardo Barrios (1860-1863)”. En Boletín AFEHC, 30. Recuperado en http://afehc-historiacentroamericana.org/index.php?action=fi_ aff\&id=1550 el 13 de julio de 2016.

6 Gaceta Oficial, Miércoles 16 de marzo de 1859, p.8.

7 Gaceta del Salvador, Miércoles 6 de abril de 1859, p.8.

8 Gaceta Oficial, Miércoles 22 de junio de 1859, p.8.

9 Gaceta Oficial, Sábado 7 de mayo de 1859, p.8.

10 Gaceta Oficial, Sábado 28 de mayo de 1859, p.8.

11 Gaceta Oficial, Sábado 16 de julio de 1859, p.8.

12 Gaceta Oficial, Sábado 30 de julio de 1859, p.8.

13 Gaceta Oficial, Sábado 20 de agosto de 1859, p.6.

14 Gaceta Oficial, Sábado 15 de octubre de 1859, p.8.

15 Gaceta Oficial, Sábado 3 de diciembre de 1859, p.8.

16 Gaceta Oficial, Sábado 17 de diciembre de 1859, p.8.

17 Gaceta Oficial, 30 de enero de 1861, p.8.

18 Gaceta Oficial, 6 de febrero de 1861, p.8.

19 Gaceta Oficial, 6 de febrero de 1861, p.8.

20 Gaceta Oficial, 20 de febrero de 1861, p.6. 
de habitación en la calle del Calvario ${ }^{21}$ don Miguel Estupinian, ${ }^{22}$ don Dionisio Aparicio $^{23}$ don Romualdo Búcaro ${ }^{24}$, don Eduardo Aragón ${ }^{25}$ y don Wenceslao Herrador ${ }^{26}$ se ponían a la disposición como abogados; por otra parte en la casa de don Irineo Ticas, situada en la calle de Marte y cerca del cuartel de Santo Domingo, doña Lorenza Tapias abrió una cafetería. ${ }^{27}$ Asimismo se sabe que don Gerónimo González trabajaba como platero ${ }^{28}$ y que don B. Pradet abrió un gimnasio en una casa de San Jacinto. ${ }^{29}$ Además, en la calle de la Libertad, esquina a la de la Unión funcionaba una pequeña abarrotería y cuartería, ${ }^{30}$ en la casa del señor Capuro se vendían sombreros juncos de todas clases, al por mayor y al detalle. ${ }^{31}$ Don Gabriel Jubin daba sus servicios como dentista en la casa de don Francisco Blanco, ubicada en la calle de la Unión frente al Lic. Francisco Dueñas. ${ }^{32}$

También en 1861 el señor Sevilla pensaba permanecer un mes en San Salvador por lo que se ponía a la orden como profesor de baile, se le podía ubicar en la casa de San Martín de la plaza de Santo Domingo. ${ }^{33}$ Don Pilar Lagos le avisaba a los dueños de billares que le habían llegado hermosas bolas de marfil. ${ }^{34}$ Por otra parte don Manuel Melara - mayordomo de la hacienda San Diego, situada a una legua de la capital, propiedad de la casa de Palacios - les ofrecía a los viajeros que llegaban al país los servicios de caballeriza y de potrero. El señor Melara señalaba que las personas que necesitaban de estos servicios se dirigieran a la mencionada casa ubicada en San Salvador. ${ }^{35}$ Don Manuel Escamilla se ponía a la disposición como carpintero, ebanista, fundidor de campanas, culebras de estaño para alambiques y reparador de instrumentos metálicos de música y de pianos..$^{36}$ En la calle de la Libertad se estableció una casa de posadas. ${ }^{37}$ En el plano educativo don José María Cáceres - director del Liceo de Santo Tomás y antiguo Contador Mayor del Estado - anunciaba que el 19 de setiembre del año en mención se abriría este establecimiento educativo. ${ }^{38}$ Además, se sabe que Don Ramón Montoya era agente comercial de navíos que llevaban añil a España. ${ }^{39}$ Por otra parte los franceses P. Delahaye y su esposa tomaron posesión del Hotel

21 Gaceta Oficial, 9 de marzo de 1861, p.6.

22 Gaceta Oficial, 13 de marzo de 1861, p.6.

23 Gaceta Oficial, 20 de marzo de 1861, p.6.

24 Gaceta Oficial, 18 de mayo de 1861, p.8.

25 Gaceta Oficial, 11 de setiembre de 1861, p.8.

26 Gaceta Oficial, 27 de noviembre de 1861, p.8.

27 Gaceta Oficial, 24 de abril de 1861, p.6.

28 Gaceta Oficial, 8 de mayo de 1861, p.8.

29 Gaceta Oficial, 3 de julio de 1861, p.8.

30 Gaceta Oficial, 3 de julio de 1861, p.8.

31 Gaceta Oficial, 6 de julio de 1861, p.8.

32 Gaceta Oficial, 20 de julio de 1861, p.8.

33 Gaceta Oficial, 20 de julio de 1861, p.8.

34 Gaceta Oficial, 6 de julio de 1861, p.8.

35 Gaceta Oficial, 6 de julio de 1861, p.8.

36 Gaceta Oficial, 21 de agosto de 1861, p.8.

37 Gaceta Oficial, 11 de setiembre de 1861, p.8.

38 Gaceta Oficial, 11 de setiembre de 1861, p.8.

39 Gaceta Oficial, 9 de octubre de 1861, p.8. 
Nacional - situado en la calle de San Francisco - por lo que anunciaba que ofrecía los servicios de este establecimiento con aseo y prontitud. ${ }^{40} \mathrm{~A}$ principios de noviembre de 1861, la compañía dramática dirigida por don Pedro Iglesias pretendía dar tres funciones en la capital, por lo que avisaba a los señores que deseaban apartar localidades que se dirigieran a la habitación de don Baudilio Alió en el Hotel Nacional. ${ }^{41}$ Otro hotel se abrió en la casa esquinera de la plaza de Santo Domingo, calle de la Independencia frente a la puerta principal del Colegio de San Agustín. ${ }^{42}$ También se puso en funcionamiento la farmacia de don Francisco García. ${ }^{43}$

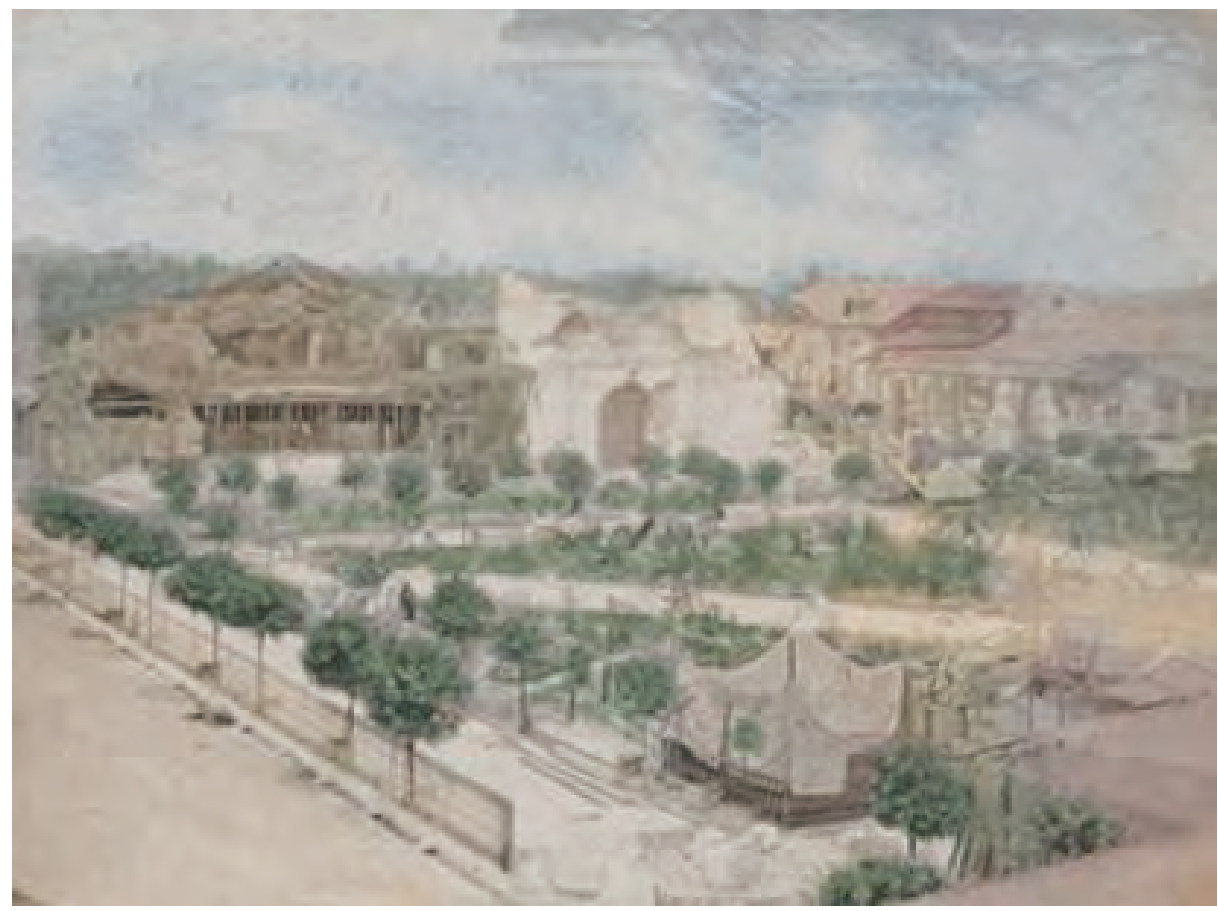

La antigua plaza de Santo Domingo, en la actualidad es ocupada por la plaza Gerardo Barrios. En esta imagen se ve en el día del terremoto del 19 de marzo de 1873.

En 1862 se abrió al público la farmacia de don Francisco García, ${ }^{44}$ Luis Huart ofrecía sus servicios como grabador y escultor. ${ }^{45}$ Además se abrió el colegio de señoritas de Fr. Bogen ${ }^{46}$ y en la casa de don Reyes Arrieta se vendía harina. ${ }^{47}$ Asimismo se tiene que funcionaba la tienda de don Juan Bandey, ${ }^{48}$ don Miguel Nugent ofrecía sus servicios como pintor de casa, rótulos, adornos y fotógrafo

40 Gaceta Oficial, 16 de octubre de 1861, p.8.

41 Gaceta Oficial, 2 de noviembre de 1861, p.8.

42 Gaceta Oficial, 14 de diciembre de 1861, p.8.

43 Gaceta Oficial, 18 de diciembre de 1861, p.8.

44 Gaceta Oficial, 1 de enero de 1862. p.8.

45 Gaceta Oficial, 8 de enero de 1862, p.8.

46 Gaceta Oficial, 8 de enero de 1862, p.8.

47 Gaceta Oficial, 22 de enero de 1862, p.8.

48 Gaceta Oficial, 15 de febrero de 1862, p.8. 
en el Hotel Salvadoreño, de la plaza de Santo Domingo. ${ }^{49}$ En esta misma plaza don Hugh G. Tonkin se ponía a la orden como carpintero, maquinista, ebanista, levantaba planos de edificios y de maquinas y dirigía obras de construcción de toda clase, ${ }^{50}$ Herbert Parry vendía artículos de metal, ${ }^{51}$ funcionaba el Hotel Salvadoreño de doña Lorenza Tapias, ${ }^{52}$ don Guillermo Eppner ofrecía sus servicios como relojero ${ }^{53}$ y funcionaba la cafetería de doña Luz Basan. ${ }^{54}$ Por otra parte, don Lois Celarié ofrecía sus servicios como relojero y joyero francés. ${ }^{55}$ También se abrió la tienda del Lic. Eugenio Aguilar. ${ }^{56}$ En la calle de la Unión funcionaba el Hotel de France del señor Fouche, esposa y compañía, ${ }^{57}$ en este mismo hotel L. González de la Torre afinaba y componía pianos. ${ }^{58}$

En la casa de don Victoriano Callejas -situada en la calle de la Independencia - don Antonino Aragón ofrecía sus servicios como profesor de inglés, francés, italiano y esgrima. ${ }^{59}$ En este mismo año funcionaba la farmacia del Lic. Francisco A. García ${ }^{60}$ En la casa de don Mariano Dorantes el Dr. Charles H. van Patten ofrecía sus servicios como dentista. ${ }^{61}$ En la tienda de sombrerería opuesta a la esquina de San Martín don P. Bordier Varoni ofrecía sus servicios como dorador y plateador de alhajas al galvanismo plástico, ${ }^{62}$ además don Aquiles Bigot trabajaba como retratista al oleo, ${ }^{63}$ en la casa de don Ignacio Pérez se vendía aceite de linaza preparado con aguarás. ${ }^{64}$ También se conoce del funcionamiento del consultorio médico del Licenciado en Medicina Darío González ubicado en su casa de habitación detrás de la catedral ${ }^{65}$ don Francisco A. García ofrecía sus servicios en la venta de la zarzaparrilla de los señores José Lara y compañía de Guatemala ${ }^{66}$ Además se sabe que se abrió la botica del señor Navarro, ${ }^{67}$ en la casa de la esquina de San Juan de Dios don Pablo Sáenz ofrecía sus servicios como profesor de piano y canto. ${ }^{68}$ Por último, se tiene información sobre el funcionamiento del Hotel y Cervecería de Kreitz y Cousin $^{69}$ y de la tienda de don Manuel Marín. ${ }^{70}$

49 Gaceta Oficial, 15 de marzo de 1862, p.7.

50 Gaceta Oficial, 15 de marzo de 1862, p.7.

51 Gaceta Oficial, 21 de mayo de 1862, p.7.

52 Gaceta Oficial, 24 de mayo de 1862, p.8.

53 Gaceta Oficial, 17 de setiembre de 1862, p.8.

54 Gaceta Oficial, 17 de setiembre de 1862, p.8.

55 Gaceta Oficial, 19 de marzo de 1862, p.7.

56 Gaceta Oficial, 16 de abril de 1862, p.8.

57 Gaceta Oficial, 16 de abril de 1862, p.8.

58 Gaceta Oficial, 17 de mayo de 1862, p.8.

59 Gaceta Oficial, 7 de junio de 1862, p.8.

60 Gaceta Oficial, 18 de junio de 1862, p.7.

61 Gaceta Oficial, 23 de julio de 1862, p.8.

62 Gaceta Oficial, 2 de agosto de 1862, p.6.

63 Gaceta Oficial, 2 de agosto de 1862, p.6.

64 Gaceta Oficial, 9 de agosto de 1862, p.8.

65 Gaceta Oficial, 6 de setiembre de 1862, p.8.

66 Gaceta Oficial, 13 de setiembre de 1862, p.8.

67 Gaceta Oficial, 18 de octubre de 1862, p.8.

68 Gaceta Oficial, 27 de noviembre de 1862, p.8.

69 Gaceta Oficial, 6 de diciembre de 1862, p.8.

70 Gaceta Oficial, 25 de diciembre de 1862, p.8. 


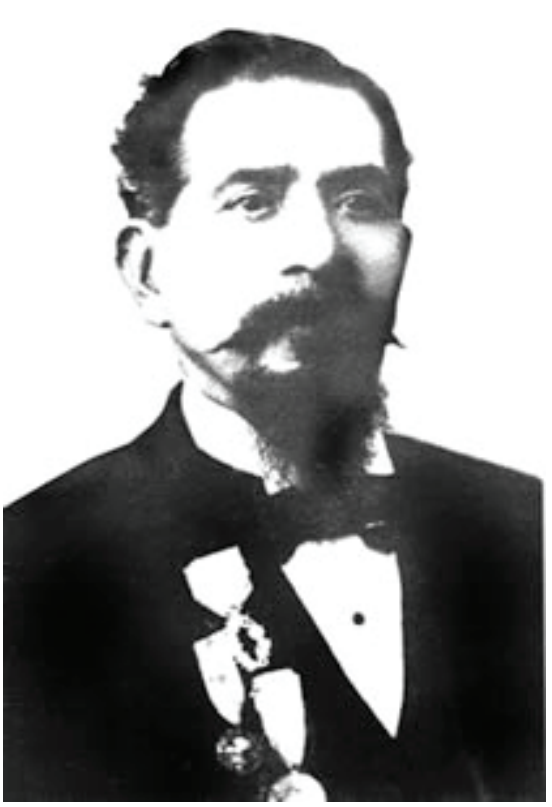

El Dr. Darío González (1835-1911) fue rector de la Universidad de El Salvador y médico personal del ex Presidente Gerardo Barrios.

Para 1863 funcionaba el consultorio del Dr. Wynne en el portal nuevo de la plaza de Santo Domingo, ${ }^{71}$ en la esquina de las calles de Amargura y Primavera funcionaba la Imprenta Litográfica de Juan Alfredo Penouil, ${ }^{72}$ don Marcos Idígoras vendía harina a ocho pesos el quintal. ${ }^{73}$ Además, ofrecían sus servicios como abogados los Licenciados Cruz Ulloa y Juan Antonio Sosa ${ }^{74}$ la casa de habitación de don Juan O Sinclair - ubicada en la calle del Comercio funcionaba como la agencia de los señores Jorge B. Kerferd y Compañía de Liverpool. ${ }^{75}$ En el Hotel de France atendían los agentes comerciales Gustavo de Belos y Compañía, ${ }^{76}$ en la calle de San Francisco frente al templo de este nombre funcionaba la panadería de Luis Giammattei, ${ }^{77}$ asimismo se sabe que funcionaba el Hotel Inglés de T.H.H. Cauty. ${ }^{78}$

La evolución de la apertura de locales profesionales y de establecimientos comerciales en San Salvador durante los años de estudio, permite afirmar que se establecieron nueve oficinas de abogados, siete hoteles, cinco consultorios médicos y cuatro establecimientos farmacéuticos. La hegemonía de los abogados era de esperarse en un contexto histórico donde está ocurriendo la

71 Gaceta Oficial, Jueves 15 de enero de 1863, p.8.

72 Gaceta Oficial, Jueves 22 de enero de 1863, p.7.

73 Gaceta Oficial, 31 de enero de 1863, p.8.

74 Gaceta Oficial, 28 de marzo de 1863, p.8.

75 Gaceta Oficial, 6 de mayo de 1863, p.8.

76 Gaceta Oficial, Sábado 16 de mayo de 1863, p.7.

77 Gaceta Oficial, Miércoles 3 de junio de 1863, p.8.

78 Gaceta Oficial, Sábado 6 de junio de 1863, pp.6-7. 
privatización de la tierra. ${ }^{79} \mathrm{El}$ centro comercial capitalino tenía su epicentro en la plaza de Santo Domingo (actual plaza Gerardo Barrios), junto con las calle del Comercio, del Calvario, de Marte, de la Libertad, de la Unión, de Amargura, de Primavera y de San Francisco.

Sobre el control social de los sectores populares debe señalarse que una parte del control social que el incipiente Estado salvadoreño comenzó a ejercer aunque muy débilmente - después de su declaratoria como República giró en torno a la morigeración de las costumbres de estos grupos sociales. En 1859 una de las principales causas que atentaban contra la moralidad era la ingesta desmesurada de licores fuertes, lo cual se debía a la venta pública y autorizada que de ellos se hacía, y a que su venta sólo se prohibía en ciertas horas en las que con dificultad se podía emplear la vigilancia policial..$^{80}$ Para 1861 el Gobernador de Sonsonate informaba que la mejora en las costumbre de los habitantes de este departamento se debía en gran parte a la influencia de los párrocos, donde se resalta la ejemplar conducta y continua predicación de estos. ${ }^{81}$ En este año el Gobernador de San Vicente don Miguel Lagos declaraba que la morigeración de las costumbres de los sectores populares se estaba haciendo con base en la eliminación de los juegos públicos de billar y lotería, aparte de que se impedía que en los garitos ingresaran hijos de dominio, otras clases de juegos prohibidos y venta de licores. Se consideraba que las peleas de gallos traían mayores males morales que los beneficios económicos que producía la miserable renta que se cobraba por su realización. ${ }^{82}$

Con respecto al área de higiene pública se sabe que en 1859, en el Departamento de Sonsonate, se había logrado que algunas enfermedades periódicas como las distintas calenturas propias de la costa, se manifestaran con un carácter benigno en los pocos casos que se habían presentado. Esto se debía a las continuas limpias de la yerba común y de muchos árboles cuya fruta se consideraba nociva como el mango y el jocote de invierno. ${ }^{83}$ En este departamento las enfermedades más comunes eran las fiebres y la disentería, ${ }^{84}$ así como el catarro, los dolores agudos de estomago y las afecciones reumáticas. ${ }^{85}$ La falta de apoyo a la morigeración de las costumbres de los sectores populares y a la higiene pública, durante los gobiernos de Barrios radica en que el Estado se concentró en la construcción de caminos, ya que para la oligarquía nacional el disponer de buenas vías

79 Lindo-Fuentes, Héctor. La economía de El Salvador en el siglo XIX. San Salvador: CONCULTURA, 2002. Acosta, Antonio. Los orígenes de la burguesía de El Salvador. El control sobre el café y el Estado. 1848-1890. Sevilla: Taller de Estudios e Investigaciones Andino-Amazónicos - Instituto de Estudios sobre América Latina 2013., y, Pérez Fabregat, Clara. "Las bases socioeconómicas de un proyecto estatal en El Salvador, 1824-1865". 2015. En Boletín AFEHC, 64. Recuperado en http://www.afehc-historia-centroamericana. org/index.php/index.php?action=fi_aff\&id=3936 el 13 de julio de 2016.

80 Gaceta Oficial, Miércoles 7 de setiembre de 1859, p.5.

81 Gaceta Oficial, 24 de abril de 1861, p.4.

82 Gaceta Oficial, 28 de agosto de 1861, p.3.

83 Gaceta Oficial, Miércoles 14 de setiembre de 1859, p.3.

84 Gaceta Oficial, 24 de abril de 1861, p.4.

85 Gaceta Oficial, 6 de noviembre de 1861, p.4. 
de comunicación era estratégica en la nueva expansión agraria y comercial orientada al mercado exterior. Por ello los presidentes de la República, que en general eran también propietarios y algunos grandes empresarios, se interesaban directamente por dicho en su gestión política y en sus visitas a los departamentos del país, asignando ingenieros que se encargasen de los caminos existentes y del trazado de otros nuevos que beneficiaran a agricultores y comerciantes. ${ }^{86}$

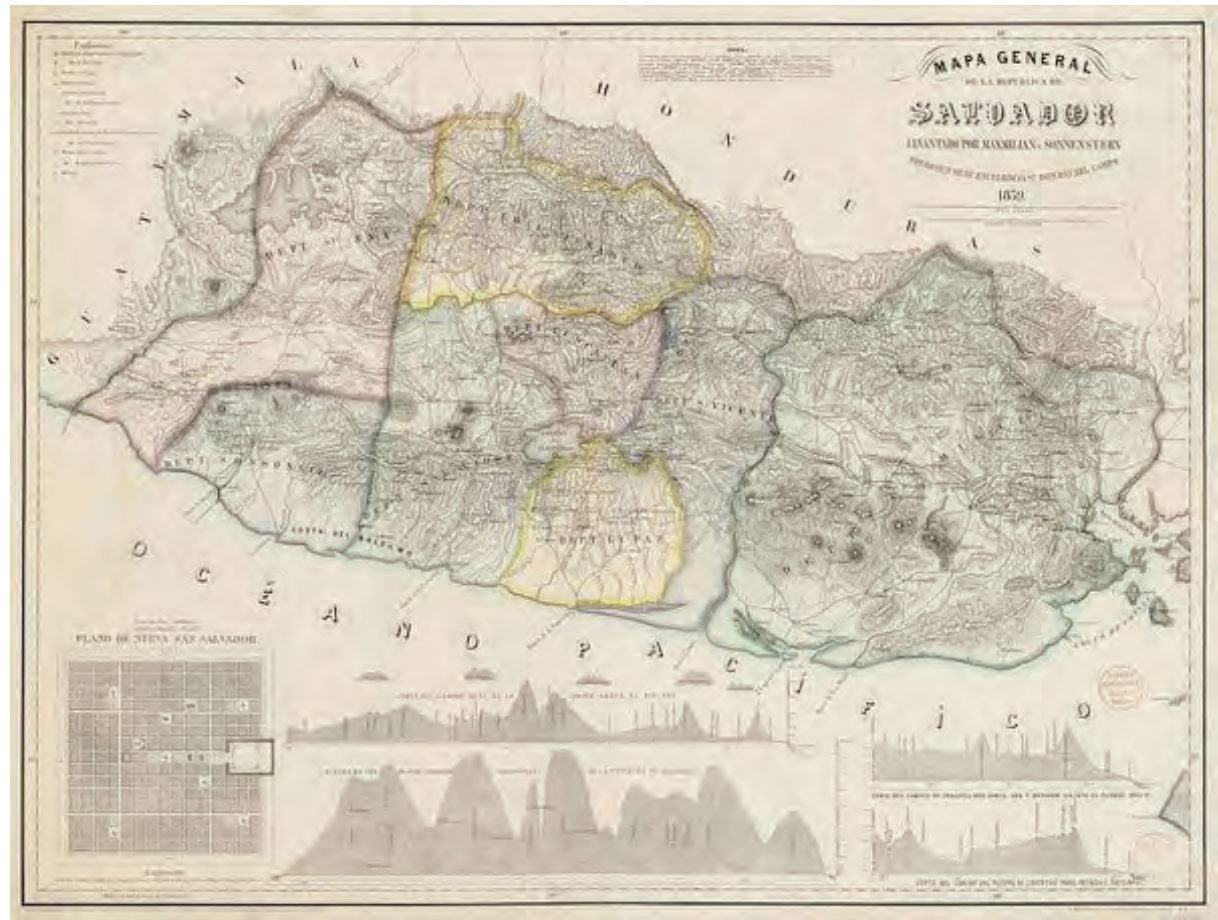

Mapa de El Salvador de 1859 hecho por el alemán Max von Sonnestern.

86 Acosta, Antonio. "Las clases dominantes, la legislación y los márgenes de la corrupción política. El Salvador a mediados del siglo XIX”. Illes Imperis, 16. p.122. Recuperado en http://www.raco.cat/index.php/IllesImperis/article/view/284887/381854 el 13 de julio de 2016. 


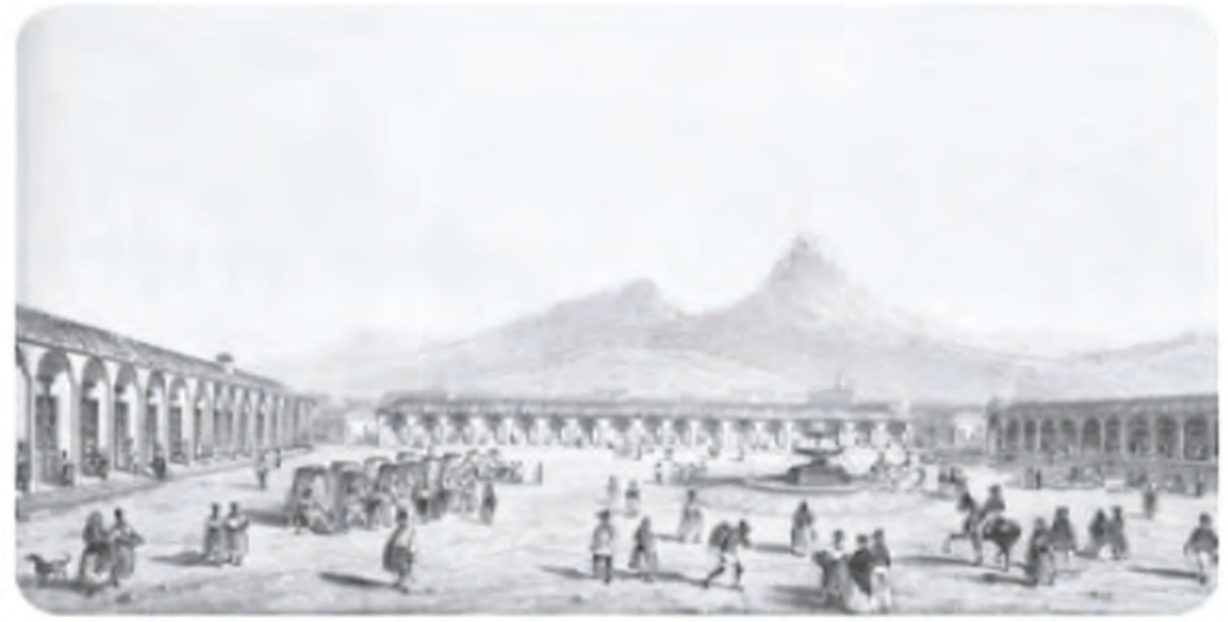

San Salvador en el siglo XIX. Vista idealizada de la Plaza Mayor - actual Parque Libertad - desde el portal de la iglesia parroquial (hoy iglesia del Rosario), en un grabado hecho en Paris por el pintor salvadoreño Francisco Cisneros (1823-1878), impreso por M. Dupressoir. En el primer plano se ve la antigua fuente, en el fondo el volcán de San Salvador.

\section{Conclusión}

El estudio del desarrollo urbanístico de San Salvador durante los gobiernos del ex presidente Gerardo Barrios en 1859 y 1861 a 1863, demuestra que los principales locales profesionales y establecimientos comerciales que se abrieron en esta urbe giraron alrededor de oficinas de abogados, hoteles, consultorios médicos y establecimientos farmacéuticos. Fueron las oficinas de abogados las que más se abrieron en la capital, lo cual se explica por la necesidad de contar con profesionales que legalizaran las transacciones de privatización de la tierra. La ebriedad y los juegos prohibidos fueron las principales entretenciones de los sectores populares que se trataron de controlar aunque la escasez de policías no permitió que este interés estatal se propagara a un nivel nacional. Las principales enfermedades de los salvadoreños a mediados del siglo XIX eran las fiebres, la disentería, el catarro, los dolores agudos de estomago y las afecciones reumáticas. La falta de apoyo a la higiene pública durante los gobiernos de Barrios se debe a que el Estado salvadoreño se concentró en la construcción de caminos, ya que para la oligarquía nacional el disponer de buenas vías de comunicación era fundamental para la economía agroexportadora añilera. 


\section{Referentes bibliográficos}

15 de septiembre de 1862. Movimiento marítimo del departamento de Acajutla. Gaceta Oficial, San Salvador, 17 de septiembre de 1862.

Acosta, A. (2013). Los orígenes de la burguesía de El Salvador, El control sobre el café y el Estado. 1848-1890. Sevilla: Taller de Estudios e Investigaciones Andino-Amazónicos - Instituto de Estudios sobre América Latina.

Acosta, A. (2016). Las clases dominantes, la legislación y los márgenes de la corrupción política. El Salvador a mediados del siglo XIX. liles Imperis. 16. 122. Recuperado de http://www.raco.cat/index.php/llleslmperis/

Acuerdo de gobierno disponiendo se cumpla exactamente lo prevenido con la ley que cita. Gaceta Oficial, San Salvador, 11 de setiembre de 1861.

Acuerdo de gobierno exigiendo el completo cumplimiento de las leyes 1 y 2 titulo 4 librto $\mathrm{C}$. recopilación patria que destina una manda forzosa y medio por ciento para la instrucción pública. Gaceta Oficial, San Salvador, 20 de agosto de 1859.

Acuerdo del gobierno disponiendo se cumpla exactamente con lo prevenido por la ley 22 , titulo 15 , libro $8^{\circ}$ de la recopilación patria. La gaceta: el vapor Columbus. Gaceta Oficial, San Salvador, 11 de septiembre de 1861.

Acuerdo del gobierno imponiendo una pena de tres a ocho días de obras públicas a los jornaleros que no cumplan con sus compromisos en lugar de la prisión que prescribe el artículo 2 de la ley, titulo 7, libro 4 de la recopilación patria. Gaceta Oficial, San Salvador, 9 de marzo de 1861.

Acuerdo del gobierno prohibiendo a los pasantes de derecho a ser procurador en juicio civil o criminal, desempeñar secretarias municipales y dirigir ningún juzgado sin previo permiso. Tratando de amistad, comercio y navegación entre la república del Salvador y Francia. Gaceta Oficial, San Salvador, 3 de diciembre de 1859.

Acuerdo del gobierno, por el cual se proyectó a los gobernadores departamentales cuiden de que los alcaldes y demás autoridades exijan el cumplimiento de las leyes sobre circulación de monedas legales. Gaceta Oficial, San Salvador, 15 de octubre de 1859.

Acuerdo del gobierno, sobre emigrados de Honduras que abusen del asilo que se les dispensa, comprendido a sus auxiliadores de esta República. Gaceta Oficial, San Salvador, 18 de mayo de 1861.

Acuerdos del gobierno de 14 de julio, reestableciendo el empleo de fiscal de Hacienda y nombrando para que ejerza al Sr. Lic. D. Manuel Suarez. Nombramiento de agrimensor del departamento de Cuscatlán. Gaceta oficial, San Salvador, 16 de junio de 1859.

Administración de la Aduana de La Unión. Gaceta Oficial, San Salvador, 6 de diciembre de 1862.

Alfaro Rivas, E. A. (2014). Las prácticas políticas en El Salvador a mediados del siglo XIX: Las redes sociales de Francisco Dueñas y Gerardo Barrios, 1854-1865. (Informe final de investigación). Universidad de El Salvador, San Salvador, SV. 
Comunicación del gobernador del departamento de Cuscatlán - retrato de S. E el presidente de la República. Relación de los trabajos del Supremo Tribunal de Justicia. Informe general de la gobernación del departamento de santa Ana. Gaceta Oficial, San Salvador, 20 de marzo de 1861.

Comunicación del Ministerio de Relaciones Exteriores de Guatemala da a las comunicaciones que le dirigió el de esta República, fecha 28 de abril y 2 de corriente. Gaceta Oficial, San Salvador, 17 de mayo de 1862.

Comunicación del supremo gobierno de Costa Rica. Comunicación del Ministerios de Relaciones Exteriores de Guatemala. Contestación. Movimiento marítimo, de los puertos de Acajutla, la Unión y La Libertad. Gaceta Oficial, San Salvador, 25 de diciembre de 1862.

Comunicaciones cruzadas entre el Ministerio General del Supremo Gobierno de la República y el Gobierno Eclesiástico. Actas. Informe de municipalidad del pueblo del Paraíso. Gaceta Oficial, San Salvador, 22 de enero de 1862.

Concordato concluido entre el supremo gobierno de la República de El Salvador y su santidad el Papa Pio IX. Gerardo Barrios capitán general del ejército Presidente de la República de El Salvador. Gaceta Oficial, San Salvador, 31 de enero de 1863.

Continuación del cuadro general de los Jefes y Oficiales de que se componen los cuerpos de cada una de las divisiones del ejército de la república. Gaceta oficial, San Salvador, 30 de julio de 1859.

Copia de la nota del cardenal Antonelli, secretario de estado de su santidad, en el que participa el señor Marques de Belmont representante de El Salvador en Roma, la mención dada por el pontífice a la cuestión del juramento exigido al Clero. Gaceta Oficial, San Salvador, 24 de mayo de 1862.

Decreto del gobierno reemplazando con un Concejo de instrucción pública el claustro de constituirlos o junta de gobierno de la Universidad de la Republica. Nombramiento de las personas que deben componer el concejo de instrucción pública Manifiesto que e señor senador General Presidente dirigió a sus conciudadanos al publicar el decreto de creación de un concejo consultivo. Gaceta Oficial, San Salvador, 7 de septiembre de 1859.

Decreto del gobierno suprimiendo el cobro de derechos en la secretaria del Tribunal Supremo de Justicia y señalado al secretario el sueldo de mil pesos anuales. Relación de los trabajos del Tribunal Supremo de Justicia. Gaceta Oficial, San Salvador, 9 de octubre de 1861

Decreto del Gobierno, convocandolas Cámaras Legislativas extraordinariamente. Decreto del Gobierno para que se tenga promulgado el Código de procedimientos civiles criminales. Gaceta Oficial, San Salvador, 15 de enero de 1863.

Decreto del Gobierno, reglamentando el cultivo y venta del tabaco en la República. Informe de gobernación del departamento de San Vicente. El gobierno de Washington y la cuestión de México. Gaceta Oficial, San Salvador, 18 de junio de 1862. 
Decreto del presupuesto para los gastos de la administración publica en el año corriente. Acuerdos del gobierno prohibiendo la introducción a la republica de individuos de Nicaragua destituyendo y removiendo algunos empleados de hacienda. Problema del señor presidente, General Don Gerardo Barrios. Gaceta Del Salvador, San Salvador, 16 de marzo de 1859.

Decreto legislativo declarado instalada la Asamblea general para secciones extraordinarias. Decreto legislativo proveyendo a la soberanía e integridad de la Nación orden legislativa señalando el día de hoy para la cláusula de las secciones. Gaceta Oficial, San Salvador, 22 de enero de 1863.

Decreto legislativo declarado la cláusula de las sesiones ordinarias de la Asamblea General. Gaceta Oficial, San Salvador, 15 de marzo de 1862.

Decreto que devuelve a San Salvador el título de capital de la república. Memoria de hacienda y guerra. Gaceta Del Salvador, San Salvador, 2 de febrero de 1859.

Del general en jefe del Ejército expedicionario en Nicaragua. Gobierno político y militar del departamento de Santa Ana. Movimiento marítimo del puerto de La Unión y de La Libertad. Gaceta Oficial, San Salvador, 6 de mayo de 1863.

Diversiones. Remitido, 1861-1862. Exposición. Tribunal de encuestas. Decadencia de México. Gaceta Oficial, San Salvador, 1 de enero de 1862.

El señor Dr. Don Mariano Padilla Baile. Manifestaciones. Movimiento marítimo del puerto de Acajutla. Gaceta Oficial, San Salvador, 8 de enero de 1862.

El último cometa. Resolución de los trabajos del Tribunal Supremo de Justicia. Informe del Gobernador del departamento de San Vicente. Recibimiento del retrato del exemo Sr. Presidente de la República, en la villa de Atiquizaya. Gaceta Oficial, San Salvador, 28 de agosto de 1861.

El vapor San Salvador. Imprenta del gobierno. Estado de El Salvador, América Central. Gaceta Oficial, San Salvador, 27 de noviembre de 1862.

Elecciones de senadores, diputados para las Cámaras Legislativas 1862. Acta de los habitantes del volcán de Santa Ana. Movimiento marítimo del puerto de Acajutla. Gaceta Oficial, San Salvador, 18 de diciembre de 1861.

Estadística parroquial. Revista general. Gaceta Oficial, San Salvador, 9 de agosto de 1862.

Fernández, J. A. (2003). Pintando el mundo de azul. San Salvador: Concultura. Gaceta editorial. Liceo de Santo Tomas. El Coronel Roberto Trigueros. Gaceta Oficial, San Salvador, 18 de octubre de 1862.

Gaceta editorial. Relación de los trabajos del Tribunal Supremo de Justicia. Movimiento marítimo del puerto de La Libertad. Gaceta Oficial, San Salvador, 16 de octubre de 1861.

Gaceta Oficial, San Salvador, 20 de febrero de 1861.

Gaceta Oficial, San Salvador, 6 de febrero de 1861.

Honduras. Movimiento marítimo del puerto de la Unión. Gaceta Oficial, San Salvador, 2 de agosto de 1862. 
Informe de la Gobernación del departamento de San Miguel. Gaceta Oficial, San Salvador, 21 de mayo de 1862.

Informe de la gobernación del departamento de Sonsonate. Administración de correos. Gaceta Oficial, San Salvador, 24 de abril de 1861.

Informe de los gobernadores de los departamentos de Santa Ana y Sonsonate. Gaceta Oficial, San Salvador, 17 de diciembre de 1859.

Informe del gobernador del departamento de Sonsonate. Gaceta Oficial, San Salvador, 14 de septiembre de 1859.

Juramento del Clero. Movimiento marítimo del puerto de Acajutla. Estudio de ingresos y egresos de la aduana de la Libertad. Gaceta Oficial, San Salvador, 6 de septiembre de 1862 .

La cuestión de México. Memorias sobre la atención por José del Valle. Gaceta Oficial, San Salvador, 23 de junio de 1862.

La Gaceta editorial. Movimiento marítimo de los puertos de La Unión y de la Libertad. Gaceta Oficial, San Salvador, 6 de junio de 1863.

La gaceta editorial. Reflexiones sobre las revoluciones políticas y la condición social de las Repúblicas hispanoamericanas. Gaceta Oficial, San Salvador, 2 de noviembre de 1861

La gaceta editorial. Sección comercial, revista mercantil de George B. Kerferd y compañía. Gaceta Oficial, San Salvador, 13 de septiembre de 1862.

La Gaceta: el excelentísimo señor presidente. El señor ministro general. El señor Vicario capitula de Honduras. Relaciones de los trabajadores del Tribunal Supremo de Justicia. Gaceta Oficial, San Salvador, 30 de enero de 1861.

La Gaceta: El Salvador. Recibimiento del retrato del Exmo. Señor Capitán General Gerardo Barrios, en Cuatepeque. Gaceta Oficial, San Salvador, 6 de julio de 1861 .

La Gaceta: el vapor Guatemala. Gaceta Oficial, San Salvador, 3 de julio de 1861. La gaceta: estreno de la iglesia barrio de Santa Lucia. El vapor Columbus. El imperio y el sacerdocio, 6 la potestad civil y potestad eclesiástica. Gaceta Oficial, San Salvador, 14 de diciembre de 1861.

La Gaceta: Honduras, articulo referente a la comunicación que el General Medina dirigió al gobernador de Chalatenango. Gaceta oficial, San Salvador, 7 de mayo de 1859 .

La Gaceta: tranquilidad pública. Gaceta oficial, San Salvador, 28 de mayo de 1859. Legislación de su Majestad Británica en El Salvador. Manifestación. ¿Por qué les llamamos Godos?. Gaceta Oficial, San Salvador, 19 de marzo de 1862.

Lindo-Fuentes, H. La economía de El Salvador en el siglo XIX. San Salvador: Concultura.

López Bernal, C. G. (2007). Compadrazgos, negocios y política: las redes sociales de Gerardo Barrios (1860-1863). Boletín AFEHC. 30. Recuperado de http://afehc-historiacentroamericana.org/index.

López Bernal, C. G. (2007). Tradiciones inventadas y discursos nacionalistas: El imaginario nacional de la época liberal en El Salvador, 1876-1932. San Salvador: Universitaria. 
Méjico: clérigos constitucionales reformistas. Gaceta Oficial, San Salvador, 27 de noviembre de 1861.

Nombramientos. Cuadro general que manifiesta las clases, nombres y colección de los generales, jefes y oficiales que hoy componen el cuartel general del ejército \& \&. Gaceta oficial, San Salvador, 22 de junio de 1859.

Noticia de Guatemala. Movimiento marítimo Puerto de La Libertad. Gaceta Oficial, San Salvador, 16 de mayo de 1863.

Orden legislativas invitando al Supremo poder Ejecutivo para nombrar una Comisión que revise la reforma sobre el Código de Procesos distintos. Gaceta Oficial, San Salvador, 15 de febrero de 1862.

Orden separando el pueblo de Comacarán del Distrito de la Unión y agregándolo al de San Miguel. Decretos permitiendo salir a trabajar, previo dictamen de Letrado y si ellos lo solicitan, a los reos no sentenciados. Acuerdos del gobierno fijando el término de treinta días para acreditar su derecho, a los militares acreedores a la Republica por sueltos devengados en la campaña de Nicaragua contra Walker: nombrado redactor de la Gaceta y Juez general de la hacienda al Lic. D. Enrique Hoyos; y haciéndoles rebaja de un diez por ciento en el pago de excesos, que verifican en créditos, a los asistentes de aguardiente. Gaceta Del Salvador, San Salvador, 6 de abril de 1859 .

Pérez Fabregat, C. (2015). Las bases socioeconómicas de un proyecto estatal en El Salvador, 1824-1865. Boletín AFEHC, 64. Recuperado de http:// www.afehc-historia-centroamericana.org/index.php/index.

Proclama. Honduras. Movimientos marítimos de Acajutla. Gaceta Oficial, San Salvador, 28 de marzo de 1863.

Proclama. Línea de vapores. Regreso del excelentísimo señor presidente de la República. Gaceta Oficial, San Salvador, 16 de abril de 1862.

Proclama. Movimiento marítimo del puerto de Acajutla. Gaceta Oficial, San Salvador, 3 de junio de 1863.

Reflexiones sobre las revoluciones políticas y la condición social de las repúblicas hispano-americanas. Gaceta Oficial, San Salvador, 8 de mayo de 1861 .

Reglamento de escuelas de primeras letras, decretado por el supremo Gobierno. Escuelas de primeras letras. Informe de la gobernación del departamento de Sonsonate. Administración de la aduana de La Unión. Imprenta del gobierno. Nacionalidades de los hijos de españoles en las repúblicas hispanoamericanas. Gaceta Oficial, San Salvador, 6 de noviembre de 1861.

Reglamento del Consejo de salubridad o protomedicato de la Republica, decretado por el Supremo Gobierno. Gaceta Oficial, San Salvador, 20 de julio de 1861.

Relación de los trabajos del Supremo Tribunal de Justicia. Informe general de la gobernación del departamento de santa Ana. Gaceta Oficial, San Salvador, 13 de marzo de 1861.

Sobre la disentería. Gaceta Oficial, San Salvador, 7 de junio de 1862.

Tratado de amistad, comercio y navegación entre la República de El Salvador y el reino de Cerdeña. El tratado celebrado en Turín. Informe del 
comisionado visitados de los pueblos de la república. Salubridad Pública. Gaceta Oficial, San Salvador, 21 de agosto de 1861.

Urbina Gaitán, Chester. (2008). Entretenimiento y Control Social: San Salvador 1847- 1875. Revista Digital. 13, 120. Recuperado de http:// www.efdeportes.com/efdl 20/entretenimiento-ycontrol-social-sansalvador-1847-1875.htm 